\title{
DEVELOPING DYNAMIC VIRTUAL ENVIRONMENTS USING HIERARCHICAL, TREE-STRUCTURED APPROACH
}

\author{
Wan Mohd Rizhan Wan Idris ${ }^{1}$, Elissa Nadia Madi ${ }^{1}$, Md Yazid Mohd Saman ${ }^{2}$ \\ ${ }^{1}$ Faculty of Informatics, Universiti Sultan Zainal Abidin, Malaysia \\ wmrizhan@unisza.edu.my, elissa@unisza.edu.my \\ ${ }^{2}$ Faculty of Science and Technology, Universiti Malaysia Terengganu, Malaysia \\ yazideumt. edu.my
}

\begin{abstract}
Virtual reality (VR) has been utilized in various applications such as in architecture, medicine, advertisement, business, entertainment, and education. In the world of simulation, VR software allows users to visualize, manipulate and interact with the computers and complex data. However, developing VR environments is costly and expensive. Highly-technical persons are needed to create the virtual objects from scratch. Once a virtual system is created, managing and modifying it creates further problems. There is a need for non-technical users to be able to create and modify their own virtual environments. This paper discusses a systematic technique to develop dynamic virtual environments and to manage virtual objects in their virtual environment. The technique is called hierarchical, tree-structured approach. To implement the technique, object-oriented programming language was used such as Java, Java 3D and Java Swing. For the usability and performance of the technique, a virtual environment has been created to become as case study. The tool has been perceived as an easy tool to use, especially for an environment in education.
\end{abstract}

\section{KEYWORDS}

Virtual Reality, Virtual Environment, Virtual Object, Tree Structure.

\section{INTRODUCTION}

The existence of virtual reality (VR) systems nowadays is resulted mostly by the development of computer technology especially in computer graphics area. Many fields such as architecture, medicine, advertisement, business, entertainment and education have explored and utilized the VR systems [1]. The existence of applications or systems based VR has changed humans' perceptions, working styles and behaviors toward better effectiveness.

There are no concise definitions of VR since it is used in different ways at different times by academics, industry professionals and the media [2]. People define VR with different terms such as telepresence, augmented reality and cyberspace [3]. Sherman and Craig [4] have defined VR as an immersion in an interactive virtual environment. Through VR, users are able to visualize, manipulate and interact with the computers and complex data to generate another world [3]. VR allows users to enter the computer-generated virtual world to respond to the users' inputs [5].The users can also explore and navigate inside the virtual world as they walkthrough in actual environment [6]. Troyer et al. [6] have described that VR is suitable for learning situations \& topics like the physical counterpart may not be available, too dangerous or too expensive. Meanwhile Artificial Reality, Cyberspace, Virtual World (VW), Virtual Environment (VE) and Synthetic Environment (SE) are the other concepts that also refer to the VR [7].

DOI : 10.5121/ijma.2011.3205 


\subsection{VOs, VEs and Other Components of VR}

One of the important components in VR is virtual object (VO) [3]. VO refers to a 3D model or $3 \mathrm{D}$ object that exists in 3D space [6]. It can also be 2D objects. Many VOs are available online and ready to use. Users may download for free or purchase the ready-made VOs to be used in the VR applications. Some of the ready-made VOs available on the internet are shown in Table 1. Figure 1 shows several examples of VOs.

Table 1. Some URLs For The Ready-Made VOs

\begin{tabular}{|l|l|}
\hline URLS & Descriptions \\
\hline http://www.amazing3d.com & $\begin{array}{l}\text { Provides services to build 3D models or VE for multimedia } \\
\text { project, movie, animation, video game, magazine, website, } \\
\text { 3D simulator and accident reconstruction. }\end{array}$ \\
\hline http://www.3dmodelfree.com/ & $\begin{array}{l}\text { Offers free 3D models for home decorations including } \\
\text { furniture, cookware, bathroom products, electronics and } \\
\text { outdoor. }\end{array}$ \\
\hline http://archive3d.net/ & $\begin{array}{l}\text { Offers free 3D models for categories of doors and windows, } \\
\text { structures, companies and collections and people. }\end{array}$ \\
\hline http://www.sharecg.com/ & Offers products of 3D models, tutorials, animation and art. \\
\hline $\begin{array}{c}\text { http://www.planit3d.com/source } \\
\text { /meshes_files/meshes.htm }\end{array}$ & $\begin{array}{l}\text { Provides free 3D products of workshop, seating, household, } \\
\text { transport, furniture, aviation, aquatics and plant. }\end{array}$ \\
\hline
\end{tabular}

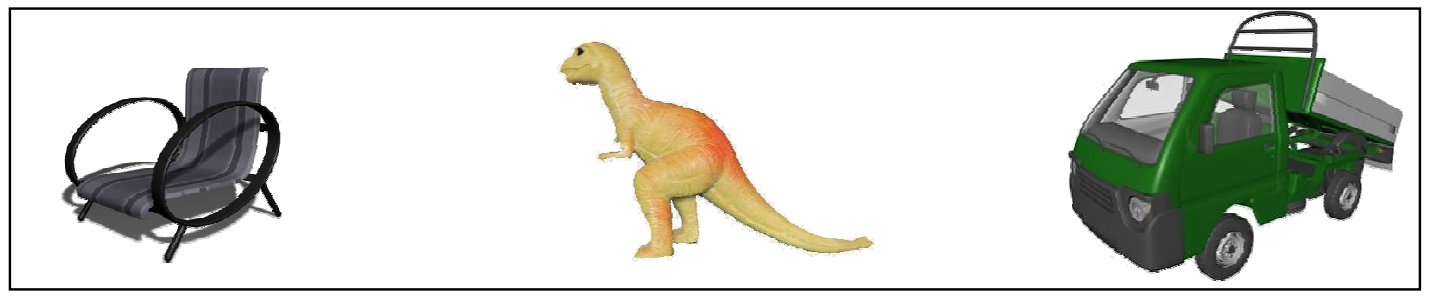

Figure 1. Several examples of VOs

Another important component in VR is virtual environment (VE). VE is a complete 3D computer environments containing $3 \mathrm{D}$ and possible also 2D objects [6][1]. Therefore, there is a need to understand the coordination system to locate precisely the VOs in the VE. The coordination of $\mathrm{x}$, $\mathrm{y}$ and $\mathrm{z}$ does not have gravity. The movements of the VOs in the VE are manipulated and controlled by the values of $\mathrm{x}, \mathrm{y}$ and $\mathrm{z}$. The $\mathrm{x}, \mathrm{y}$ and $\mathrm{z}$ can also give the values of width, height and depth of the objects. Figure 2 illustrates the coordination of $\mathrm{x}, \mathrm{y}$, and $\mathrm{z}$.

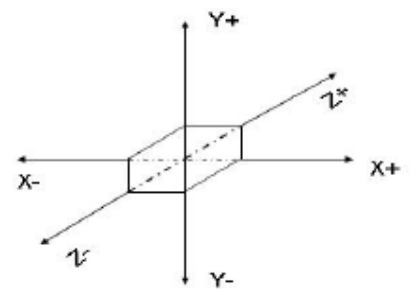

Figure 2. The Coordination of $\mathrm{X}, \mathrm{Y}$ and $\mathrm{Z}$ in $3 \mathrm{D}$ Space 
There are three other components in VR; viewing, walkthrough and manipulation. Viewing component enables all operations or tasks exercised in the VE to be visualized. In general, the viewing component can help explain the usage of terms; field of view; position and orientation; and distance of the objects. It is possible for the VR systems having several viewings or commonly pointed out as multi-views or multi-displays. Walkthrough component allows users to explore and navigate in the VE [3]. The users may go forward and backward or may turn left and right as if they walk or run in the real environment. It is suitable for the visualization and evaluation purposes in the construction, tourism and research fields. Manipulation component refers to the users' interactions with VOs in the VE [3]. Some examples of activities describing this component are selecting an object, changing the position and orientation of an object, rotating and scaling an object. This component mainly highlights the particular ways users interact with VOs in VE.

\subsection{Motivations}

Normally, the 3D objects are constructed and modeled in various forms and shapes using 3D Tools such as 3ds Max, AC3D, Alladdin4D, Cinema4D, LightWave 3D, Maya or other 3D Tools [8] which are commercially available in the market. However, the high costs of the tools become the main issue. They also need highly technical efforts as well as relevant knowledge in creating a 3D object. Users need to spend sufficient times to complete a VO as desired. Users may feel frustrated when the desired form and shape of VO cannot be produced on time.

Typically, the complete VOs and/or ready-made VOs are placed in their VEs using the 3D Tools as well. The provided utilities in the 3D Tools may arrange the VOs in terms of locations and orientations. To locate accurately a VO at a particular place in the VE, normally the VO needs to be loaded one-by-one into the system. Therefore, another study mechanism is needed to manage and arrange the VOs in the VE especially when involving many VOs in a certain time. Improper management of the VOs can cause the VE to be crowded with the undesired VOs. Indirectly, this matter also contributes to delivering information unsystematically.

Sometimes, the VOs have links to other sub-VOs or sub-information. They are connected among them directly through files or URL. Improper management of the links will cause the sub-VOs or the sub-information cannot be accessed. This situation reveals to the users about the weaknesses of the operability and applicability for the system. These weaknesses may reduce the numbers of users to use the system.

Adding new information, deleting undesired information and editing existing information are crucial activities needed for modifications of the VOs in the VE. However, such modifications are limited and difficult in the VE which is full with many VOs. The change of a certain VO may affect the other VOs in the VE. Thus, the important information that should be perpetual is changed as well.

In this paper, we present the related works in Section 2 focusing on the managing VEs or VOs techniques. The proposed technique called Hierarchical, Tree-Structured Approach is discussed in detail in Section 3. The modules involved to create dynamic VEs and a case study are presented in Section 4. Section 5 describes on results and discussions for the created VEs using the proposed approach. We conclude our paper with conclusions and future works.

\section{RELATED WORKS}

VR has been an active area of research. Several related works focusing on managing VOs and VEs as well as the VR components have been highlighted. Dynamic Electronic Catalogs system 
have utilized pre-made files for creating VOs and VEs, walkthrough mechanism for navigation in the VE, rotation operation for manipulation of VOs and single-view mode for visualization [9]. In Virtual Community Trials Platform, a walkthrough method called Community 3D Walkthrough System has been proposed for moving, recording key walkthrough position nodes and playing back 3D animation with a walkthrough path. Only single-view mode has been utilized for visualization [10].

In V-REALISM system [11], a tree structure is used to manage and manipulate the imported geometric models in the VE. The models can be classified into environment model and system model in the tree structure. The environment models are used to simulate the maintenance environment and facilitate the visualization and exploration. The system models are further decomposed into component and subassembly models. Each component model is represented as a geometric mesh surface model which is displayed as a set of triangular surfaces. The smallest unit of a geometric model is triangular surface that is depicted as "TriUnit" in the hierarchy [11]. This system however can produce only a VE in a certain time.

Yuan et al. [12] have proposed assembly guidance techniques using the Virtual Interaction Panel (VirIP) and the Visual Assembly Tree Structure (VATS). VirIP is used to track the real-time interaction pen using a Restricted Coulomb Energy (RCE) neural network. VATS is used to represent the assembly sequences of complex products. VATS specifically works for management of assembly information and retrieval for the AR-assisted assembly guidance system. VATS comprises nodes that represent the assembly information such as geometric properties of an assembly part, sub-assembly and so on.

The sample tree proposed by Klein et al. [13] is used to store a number of polygons in a scene for rendering complex environment. The rendering process that provides caching mechanism allows only few nodes to be loaded from one frame to the next frame. This caching mechanism has employed the notion "Area Of Interest" (AOI) to use and render the objects in corresponding area.

Meanwhile, Java 3D features have been used as main hierarchy structure in managing and creating the virtual anatomic models [16]. The scene graph concept has been used to represent the multi-modal anatomy models. Group node in the structure is similar to Java 3D scene graph TransformGroup node and Geometry nodes are composed by the geometry node in Java 3D with some functions needed by other modal data.

The prior researches have utilized the tree structure in VR applications for certain tasks as described above. The use of the tree structure however, is not optimally or fully implemented for developing and managing VOs and VEs. In this paper, a technique using the tree structure for developing dynamic VEs as well as managing VOs is discussed in detailed.

\section{Hierarchical, Tree-STRUCTURED APPROACH}

A hierarchical, tree-structured approach has been utilized in this study specifically for creating dynamic VEs as well as managing the VOs in the VE. In computer science, a tree is a widelyused data structure that emulates a tree structure with a set of linked nodes [15]. Several important nodes in the tree structure are root, parent, children and leave nodes. Each node may have parent node and zero or more children nodes. The top node is called root node with the other nodes being connected beneath it [16]. The very bottom nodes of the tree or the nodes that have no children are called leaves nodes [16]. Figure 3 demonstrates the nodes in the tree structure. 


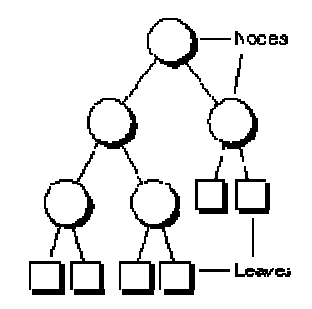

Figure 3. Elements In A Tree Structure

Through mathematical definition [17], a tree $T$ is a finite, non-empty set of nodes,

$$
T=\{r\} \cup T_{1} \cup T_{2} \cup \ldots \cup T_{n}
$$

With the following properties:

- A designated node of the set, $r$, is called the root of the tree; and

- The remaining nodes are partitioned into $n \geq 0$ subsets, $T_{1}, T_{2}, \ldots . ., T_{n}$, each of which is a tree.

For convenience to denote the tree $\mathrm{T}$, the following notation is used,

$$
T=\left\{r, T_{1}, T_{2}, \ldots . ., T_{n}\right\}
$$

The other important terms [17] can be produced from (2):

- The degree of a node is the number of sub-trees associated with that node. For example, the degree of tree $T$ is $n$.

- A node of degree zero has no sub-trees. Such node is called a leaf.

- Each root $r_{i}$ of sub-tree $T_{i}$ of tree $T$ is called a child of $r$. The term grandchild is defined in a similar manner.

- The root node $\mathrm{r}$ of tree $T$ is the parent of all the roots $r_{i}$ of the sub-trees $T_{i}, l<i \leq n$. The term grandparent is defined in a similar manner.

- Two roots $r_{i}$ and $r_{j}$ of distinct sub-trees $T_{i}$ and $T_{j}$ of tree $T$ are called siblings.

The implementation of the tree structure through our approach allows the root node, $\mathrm{r}$ to become main VE. The sub-nodes in the tree may represent the other VEs, $T_{1}, T_{2}, \ldots . ., T_{n}$ or VOs. Basically, parent node may turn out as VE and child node may become VO. The leave node certainly represents as VO.

Our approach allows VOs to be split into a number of categories or groups. The categorizations can be made when child nodes or sub-nodes are inserted under a particular parent node. In this case, the child nodes are said to be grouped or classified in their own parent nodes' category. The parent nodes that contain of their child nodes are defined as a collection of groups or categories. 
Categorizing the objects may also produce a number of levels or depths. Figure 4 shows the nodes in the tree structure that can be split into a number of groups based on parent-child concept. Each group then is called Area of Interest (AOF). For instances, Area 1 canvases the root node as parent while nodes 1, 2 and 3 as its children; Area 2 contains node 1 as parent node while its children are nodes 1.1, 1.2 and 1.3; and so do for the other areas. From the results, the VOs and VE can be defined and created successfully to be placed in the VR system. In this case, any parent node will be a VE while the child nodes will turn out to be the VOs in the VE (parent node).

More details of information can be inserted especially for each VO in each area using our technique. By separating the areas (Figure 5), all nodes that resident inside each area seem more obvious without much complexity. The VOs perhaps may get hold of complete descriptions to be displayed and delivered as useful knowledge.

Besides, any modification or change on either information or VOs especially in terms of their positions and orientations can be made independently and easily. The modification only affects at the particular infected area. The rest of areas are not influenced by the modification.

A VO in the tree structure can also be reused or repeated. There is no limitation in the duplication of VOs. The duplicated VO then can be manipulated to produce a unique VO that differs from the other VOs. For such purpose, a mechanism in our technique to manipulate the VOs in terms of rotation, translation scale is used.

Through our technique, the VOs is managed and arranged in synchronized. A systematical flow of VOs' node can be seen in the tree structure from the root node till the leaves nodes. Each area of interest produced according to parent-child concept is managed in sorted. Therefore, it leads to the synchronization of VEs.

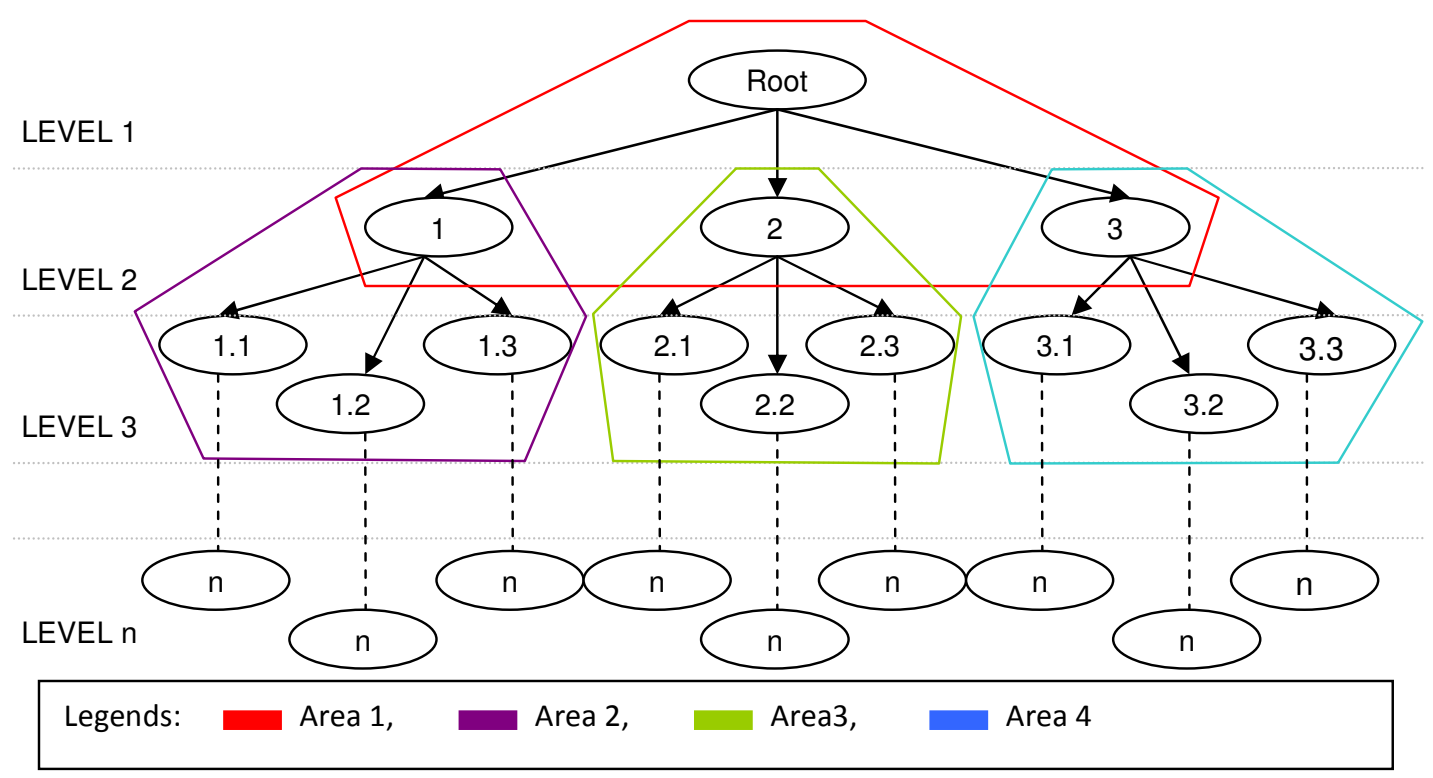

Figure 4. Levels in the tree structure 


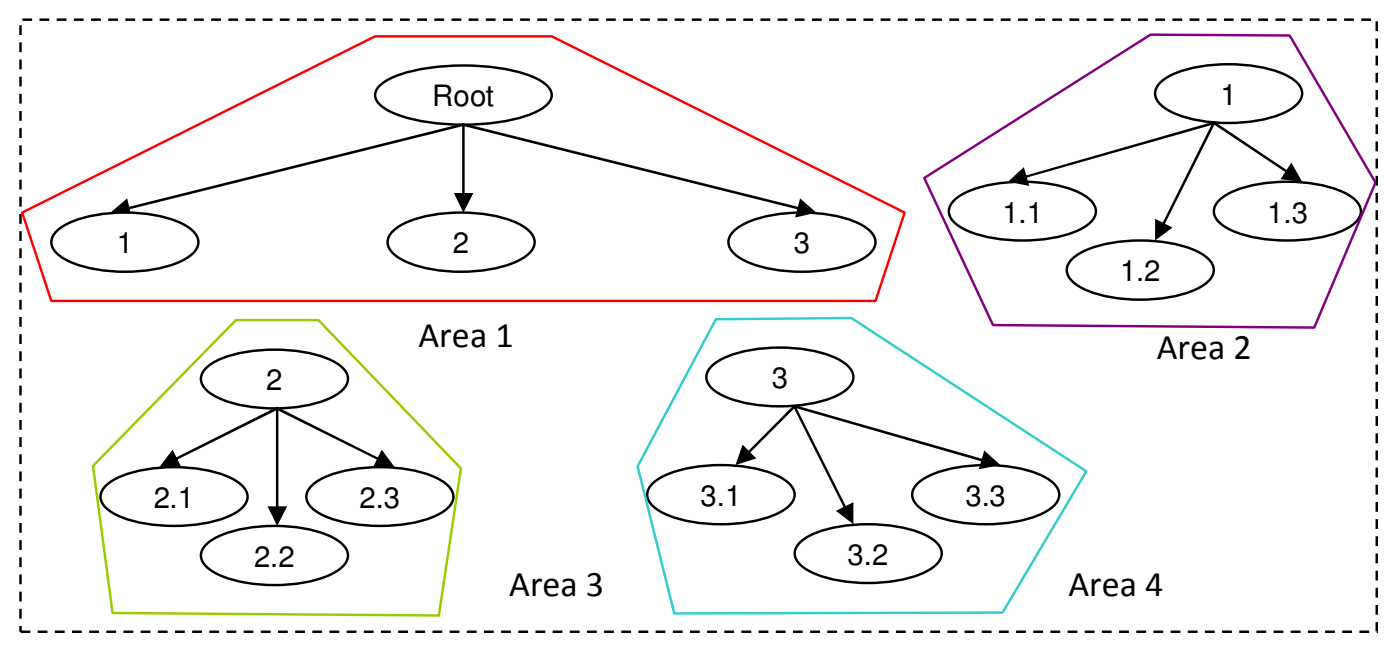

Figure 5. Areas of interests in tree structure

\section{EXPERIMENTS}

As an experiment, modules involved in the creation and management of VEs, topic of amino acids group as a case study, type of VO file format used in the VR system and methods to develop VEs for the case study using the utilized approach are explained in detailed.

\subsection{Modules of Creating and Managing Virtual Environments}

There are four modules involved in creating dynamic VEs and managing VOs in VE as shown in Figure 6.

Module 1: Initializing interface of system (Loading Editor)

Step 1: Finding \& Selecting VOs

Step 2: Listing Names of VOs

Step 3: Displaying Preview Screen of VOs

Module 2: Developing a tree data structure (Hierarchical, Tree-Structured Editor)

Step 1: Adding, removing and updating VOs

Step 2: Creating graphical tree structure

Module 3: Organizing VOs (Organizing VOs Editor)

Step 1: Multi-Monitor Screens

Step 2: Translation \& Scale operations

Step 3: Recording VOs' Information

Module 4: Viewing VE (Viewing Editor)

Step 1: Single-View \& Multi-Views

Step 2: Walkthrough in VE

Step 3: Manipulation of VOs

Figure 6. Four modules involved in creating and managing VEs

In the first module, an interface of virtual reality system called Loading editor is initialized. This interface allows users to search the location of VOs either in users' computers or in the server and select the desired VOs to be loaded in the system; list the names of VOs that are successfully loaded; and display the sample of VOs selected from the list. 
The second module provides the use of data structure using hierarchical, tree-structured editor. The users can create the graphical tree structure through several types of operations provided in this editor such as adding new VOs in the tree structure, adding new group of VOs, removing unneeded VOs and clearing all VOs in the tree structure.

Organizing VOs editor in the third module works to manage the VOs in the VE in terms of position and orientation. The users can view a VE in multi-monitor screens to precisely locate the VOs at the desired places. Each monitor screen projects different viewing such as front, left, top and perspective views. Through translation and scale operations, the users can move the selected VO at new location in the VE and resize VO. Information about VOs such as file, caption, description, parent, path, location, scale and rotation also can be saved systematically in the text file with extension *.hevo for reference, distribution and display in future. Thus the users do not need to rebuild the VE from the beginning.

The last module allows the users to view the final results of VEs either in single-view mode or multi-views mode. They can walkthrough in the VE using the arrow keys on the keyboard. The mouse is used to allow the users manipulating and interacting with VOs in the VE. Figure 7, 8, 9 and 10 show the interfaces of editors in the VR system which implement the four modules as described above.

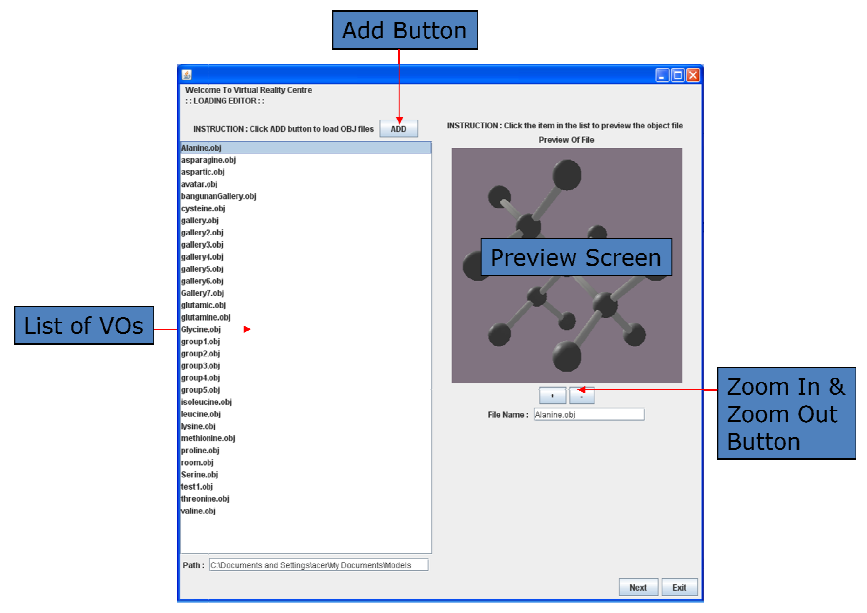

Figure 7. Interface of loading editor 
The International Journal of Multimedia \& Its Applications (IJMA) Vol.3, No.2, May 2011

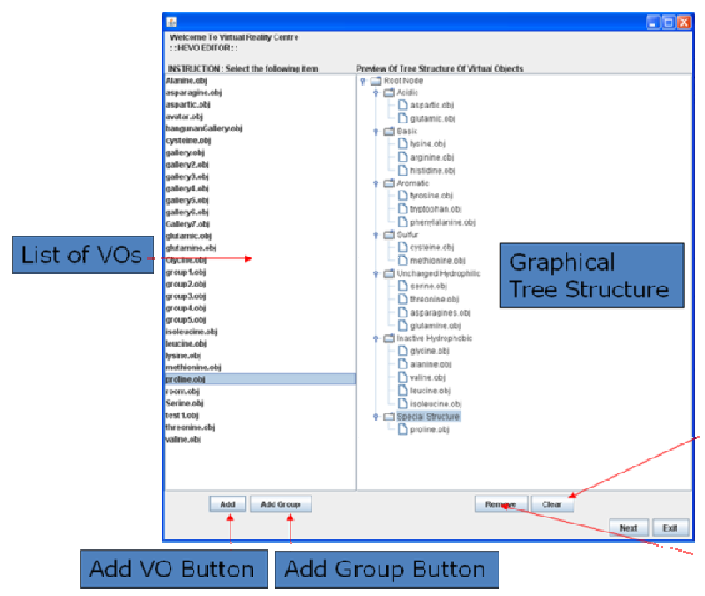

Figure 8. Interface of hierarchy, tree-structured editor

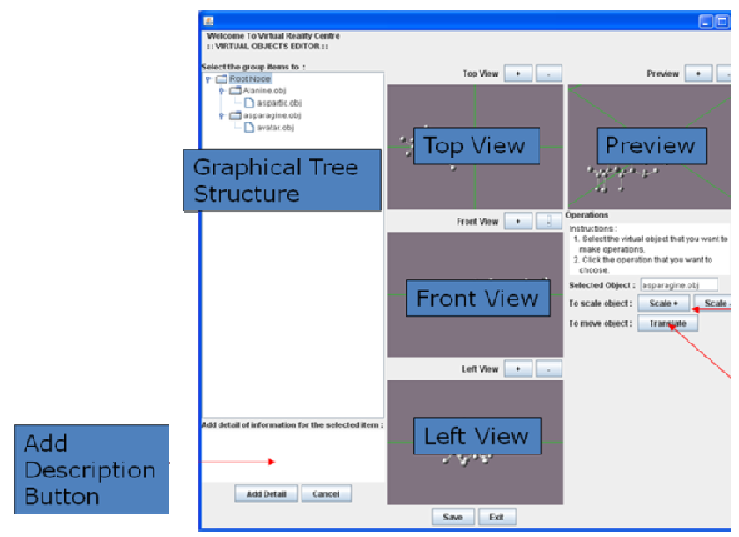

Figure 9. Interface of organizing VOs editor

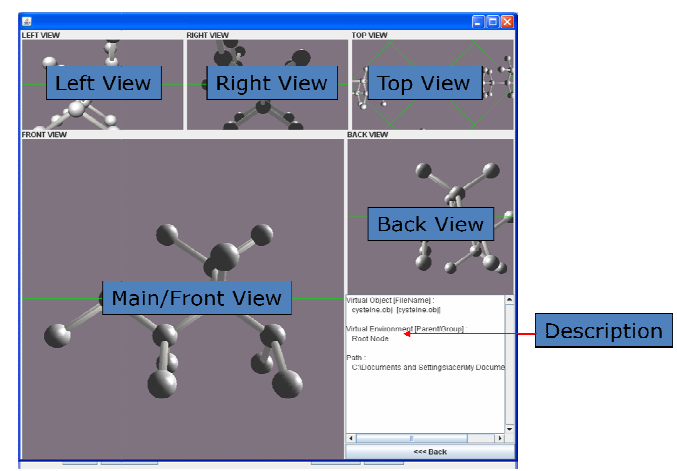

Figure 10. Interface of viewing editor

\subsection{Amino Acids Group}

A topic of amino acids group has been chosen in testing the VR system using hierarchical, treestructured approach. Amino acids are small molecules that may structure proteins [18]. By 
forming short polymer chains called peptides or polypeptides in turn, they construct proteins. In fact, the amino acids become the basic structural building units of proteins [19]. All molecules contain three important parts; an Amine group, a Carboxyl group and R group. Both the Amine group and the Carboxyl group belong to all amino acids. However, $\mathrm{R}$ group varies for individual amino acid. In fact, each molecule can be recognized through this $\mathrm{R}$ group. The Amine group contains elements $\mathrm{NH} 3+$ while the Carboxyl group contains COO- [18]. A different side chain is represented by $\mathrm{R}$ group specifically to each amino acid. Figure 11 shows the basic structure for amino acids.

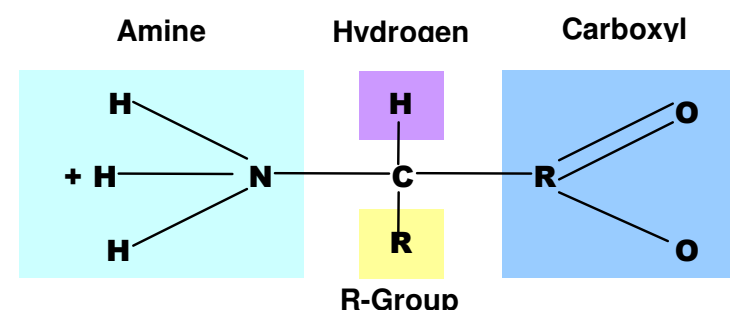

Figure 11. The structure of all amino acids

There are twenty amino acids encoded by the standard genetic code which are Argynine (Arg/R), Glutamine (Gln/Q), Phenylalanine (Phe/F), Tyrosine (Tyr/Y), Lysine (Lys/K), Glycine (Gly/C), Alanine (Ala/A), Histidine (His/H), Proline (Pro/P), Glutamic Acid (Glu/E), Aspartic Acid (Asp/D), Threonine (Thr/T), Methionine (Met/M), Leucine (Leu/L), Asparagine (Asn/N), Isoleucine (Ile/I), Tryptophan (Trp, W), Serine (Ser/S), Cysteine (Cys/C), Valine (Val/V) [19, 20, 21]. The twenty amino acids then are classified into five categories as shown in the Table 2.

Table 2. The categories of amino acids

\begin{tabular}{|c|c|c|c|c|c|}
\hline Categories & $\begin{array}{c}\text { Polar With } \\
\text { Negative } \\
\text { Charged }\end{array}$ & $\begin{array}{c}\text { Polar With } \\
\text { Positive } \\
\text { Charged }\end{array}$ & Aromatic & $\begin{array}{c}\text { Polar } \\
\text { Uncharged }\end{array}$ & Non-Polar \\
\hline Molecules & $\begin{array}{l}\text { Aspartic Acid } \\
\text { Glutamatic- } \\
\text { Acid }\end{array}$ & $\begin{array}{l}\text { Lysine } \\
\text { Arginine } \\
\text { Histidine }\end{array}$ & $\begin{array}{l}\text { Tyrosine } \\
\text { Tryptophan } \\
\text { Phenylalanine }\end{array}$ & $\begin{array}{l}\text { Serine } \\
\text { Threonine } \\
\text { Asparagines } \\
\text { Glutamine } \\
\text { Cysteine } \\
\text { Proline }\end{array}$ & $\begin{array}{l}\text { Glycine } \\
\text { Alanine } \\
\text { Valine } \\
\text { Leucine } \\
\text { Isoleucine } \\
\text { Methionine }\end{array}$ \\
\hline
\end{tabular}

\subsection{OBJ File Format}

In the VR system, ready-made VOs for the amino acids group have been utilized. The type of file format for the $\mathrm{VO}$ is Wavefront or OBJ file format. Wavefront or OBJ file format is a geometry definition file format. It is used for its advanced visualizer animation package [22] that purposes especially in storing and exchanging 3D data [23]. Many 3D graphics application vendors can utilize and support the OBJ file format [22].

This file format produces two types of files for each VO which in respect contain the extensions of $(* . o b j)$ for object file and (*.mtl) for material file [25, 26]. Both files always need to be along with each other. 


\subsection{Development of Amino Acids Group Virtual Environments}

Through our approach, several VEs of the amino acids have been created based on the classification of the amino acids group. In this case, there are three layers in the hierarchical tree structure. The first layer is where the root takes place. The root contains six children which refer to a Gallery Building and five classes of the amino acids i.e: Polar with Positive Charge, Polar with Negative Charge, Polar Uncharged, Non-Polar and Aromatic. To develop the model of each group, new group utility in the VR system is used. The name of new group then is changed based on the classes of amino acids. It is because the group has no model to represent itself in the VE. In the last layer, all children or VOs are placed and positioned according to their groups respectively. Figure 12 depicts the tree structure for the amino acids group using our approach.
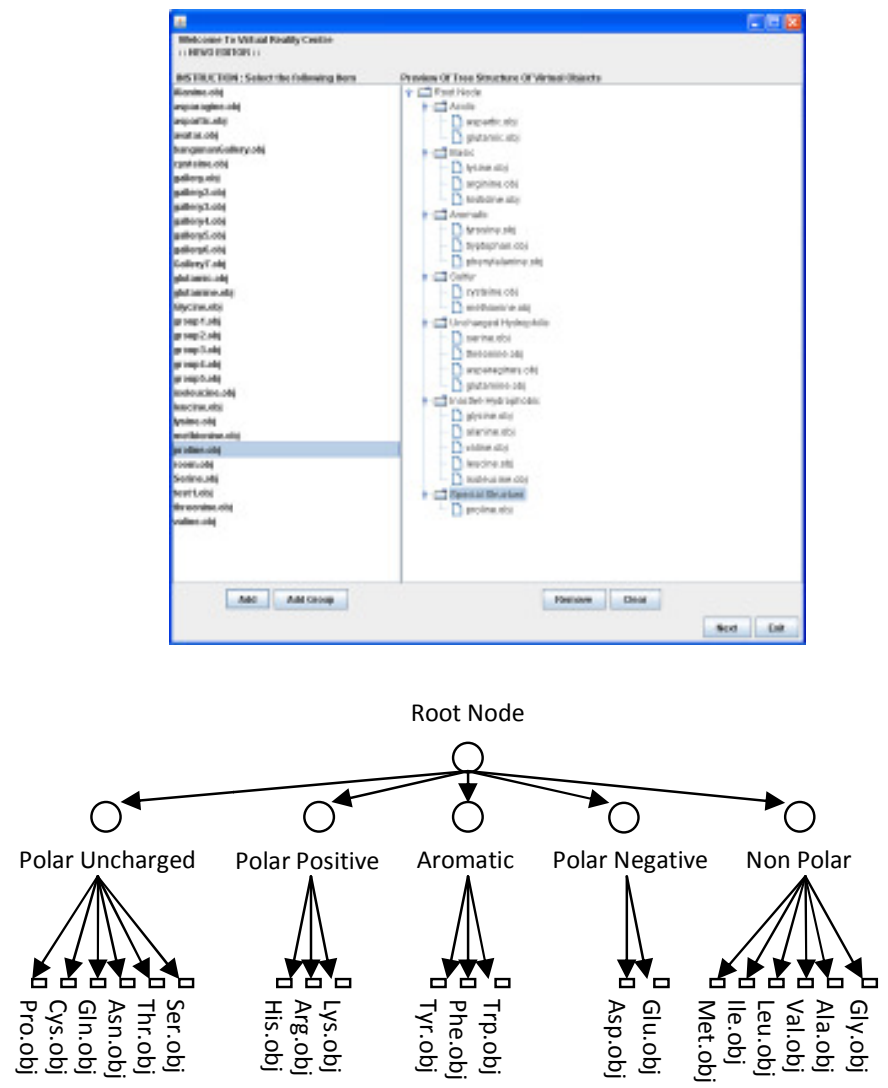

Figure 12. Tree structure of amino acids group

Through the tree structure, the VOs and VE components are able to be identified. In this case, all nodes that have been parents in each group become the VEs which are inhabited by their own VOs. Meanwhile, the VOs refer to the contents of the parents' children. Therefore the root and the groups have been determined to be the VEs.

Let the root denoted as $r$, Polar Uncharged as $\mathrm{VO}_{1}$, Polar Positive as $\mathrm{VO}_{2}$, Aromatic as $\mathrm{VO}_{3}$, Polar Negative as $\mathrm{VO}_{4}$ and Non Polar as $\mathrm{VO}_{5}$. Each leave node beneath its parent node is labelled as $\mathrm{VO}_{\mathrm{Tn}, \mathrm{i}}$ where $\mathrm{n}=\{1,2,3, \ldots\}$ and $\mathrm{i}=\{1,2,3, \ldots\}$. For storing hierarchical data in database, the Pre-Order Traversal is used as follow (3) using (2). A Pre-Order Traversal is an efficient way of visiting all the nodes of a tree. It will trace the outline of the tree starting from the upper left next 
to the root, identifying nodes as travel downward on the left side of the node. The first node here is the root node.

$$
\begin{aligned}
& T_{r}=\left\{r, T_{V O_{1}}, T_{V O_{2}}, T_{V O_{3}}, T_{V O_{4}}, T_{V O_{5}}\right\}
\end{aligned}
$$

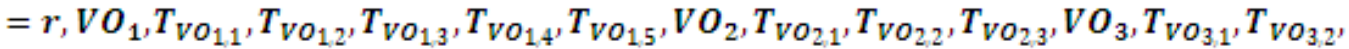

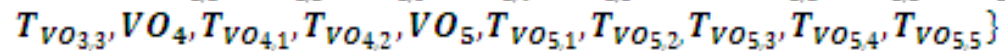

$$
\begin{aligned}
& =r, V O_{1}, V O_{1,1}, V O_{1,2}, V O_{1,3}, V O_{1,4}, V_{1,5}, V O_{2}, V O_{2,1}, V O_{2,2}, V O_{2,3}, V O_{3}, V O_{3,1}, V O_{3,3} \text {, } \\
& \left.\mathrm{VO}_{4}, \mathrm{VO}_{4,1}, \mathrm{VO}_{4,2}, \mathrm{VO}_{5}, \mathrm{VO}_{5,1}, \mathrm{VO}_{5,2}, \mathrm{VO}_{5,3}, \mathrm{VO}_{5,4}, \mathrm{VO}_{5,5}, \mathrm{VO}_{5,6}\right\}
\end{aligned}
$$

\subsection{Outputs of Amino Acids Group Virtual Environments}

As illustrated in Figure 13, there are a Gallery and five other categories of amino acids in a VE. These categories are placed inside the Gallery as if they are exhibited in it. These five categories in the Gallery refer to Polar Positive Charge, Polar Negative Charge, Non-Polar, polar uncharged and aromatic. Each of them has its own sub-nodes or child nodes. Thus the categories can have their own VEs when user activates them. Figure 14(a), Figure 14(b), Figure 14(c), Figure 14(d) and Figure 14(e) show the VEs for each category and their VOs.
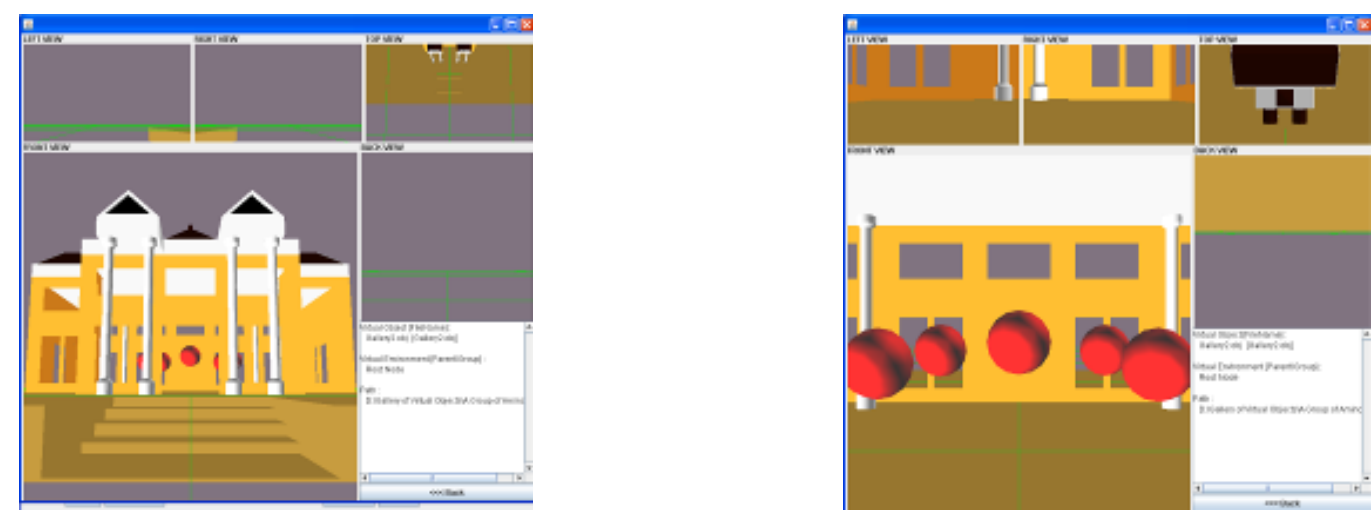

Figure 13. A gallery and five main categories

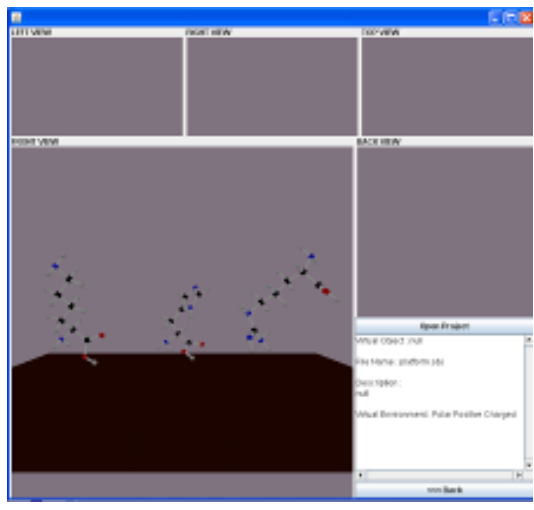

(a) VE of polar positive

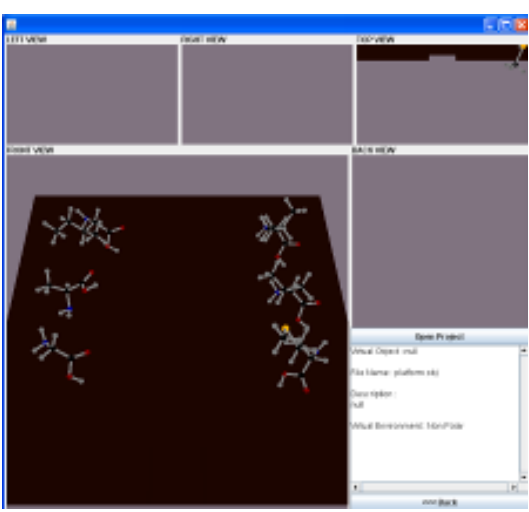

(b) VE of non-polar 
The International Journal of Multimedia \& Its Applications (IJMA) Vol.3, No.2, May 2011

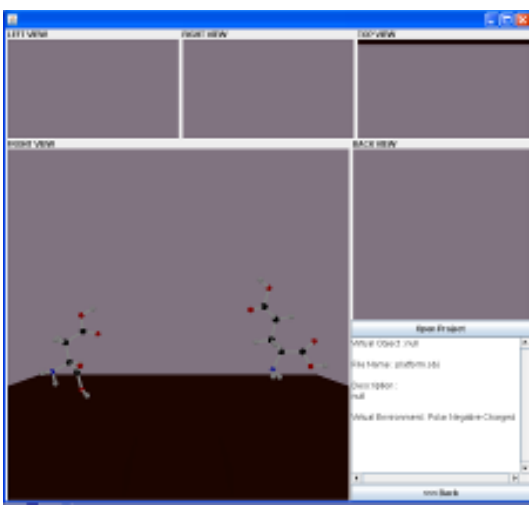

(c) VE of polar negative

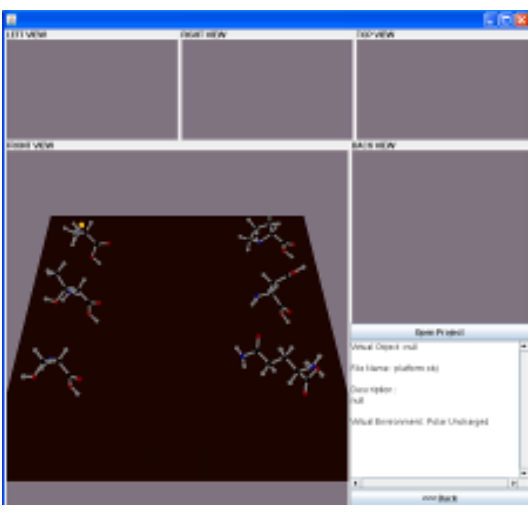

(d) VE of polar uncharged

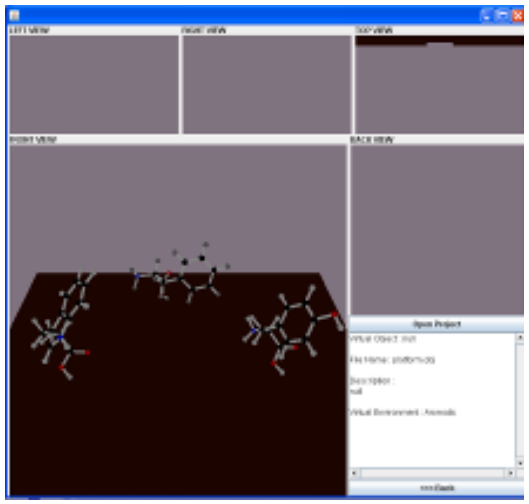

(e) VE of aromatic

Figure 14. VEs for the categories of VOs

\section{RESUlTS \& DiSCUSSIONS}

After testing the selected topic in the VR system using the hierarchical, tree-structured approach, analysis for the outputs is then implemented through qualitative and quantitative methods. The quantitative method is used to obtain the amount of capacities generated by each VE in the VR system. Meanwhile the qualitative method is implemented to evaluate the usability of VR system using the proposed approach.

\subsection{Quantitative Analysis}

The input data used in the VR system contains of the ready-made VOs for representing the molecules and the primitive objects created by the tool provided in the VR system for representing the groups of molecules. Each VE comprising a number of VOs beneath it generates an amount of storage when it is activated. Table 3 shows the total of storage generated for each projected VE in the VR system. 
The International Journal of Multimedia \& Its Applications (IJMA) Vol.3, No.2, May 2011

Table 3. The total of storage generated for each projected VE

\begin{tabular}{|c|c|c|c|c|c|c|c|c|}
\hline VEs & $\begin{array}{c}\text { No } \\
\text { of } \\
\text { VOs }\end{array}$ & Name of VOs & $\begin{array}{c}\text { OBJ } \\
\text { file } \\
\text { name }\end{array}$ & $\begin{array}{c}\text { OBJ } \\
\text { file size }\end{array}$ & $\begin{array}{c}\text { MTL } \\
\text { file } \\
\text { name }\end{array}$ & $\begin{array}{c}\text { MTL } \\
\text { file } \\
\text { size }\end{array}$ & $\begin{array}{c}\begin{array}{c}\text { Size of } \\
\text { files } \\
\text { (Obj + } \\
\text { MTL) }\end{array} \\
\end{array}$ & $\begin{array}{c}\text { Total of } \\
\text { sizes }\end{array}$ \\
\hline Root & 6 & $\begin{array}{l}\text { Gallery } \\
\text { *Polar Negative } \\
\text { *Polar Positive } \\
\text { *Aromatic } \\
\text { *Polar } \\
\text { Uncharged } \\
\text { *Non-Polar }\end{array}$ & $\begin{array}{c}\text { Gal.obj } \\
- \\
- \\
- \\
- \\
-\end{array}$ & $232 \mathrm{~KB}$ & $\begin{array}{c}\text { Gal.mtl } \\
- \\
- \\
- \\
- \\
-\end{array}$ & $\begin{array}{r}1 \mathrm{~KB} \\
- \\
- \\
- \\
- \\
-\end{array}$ & $\begin{array}{c}233 \mathrm{~KB} \\
- \\
- \\
- \\
- \\
-\end{array}$ & $233 \mathrm{~KB}$ \\
\hline $\begin{array}{l}\text { Polar } \\
\text { Negative }\end{array}$ & 2 & $\begin{array}{l}\text { Aspartic Acid } \\
\text { Glutamatic } \\
\text { Acid }\end{array}$ & $\begin{array}{l}\text { Asp.obj } \\
\text { Glu.obj }\end{array}$ & $\begin{array}{l}414 \mathrm{~KB} \\
490 \mathrm{~KB}\end{array}$ & $\begin{array}{l}\text { Asp.mtl } \\
\text { Glu.mtl }\end{array}$ & $\begin{array}{l}1 \mathrm{~KB} \\
1 \mathrm{~KB}\end{array}$ & $\begin{array}{l}415 \mathrm{~KB} \\
491 \mathrm{~KB}\end{array}$ & $906 \mathrm{~KB}$ \\
\hline $\begin{array}{l}\text { Polar } \\
\text { Positive }\end{array}$ & 3 & $\begin{array}{l}\text { Lysine } \\
\text { Arginine } \\
\text { Histidine }\end{array}$ & $\begin{array}{l}\text { Lys.obj } \\
\text { Arg.obj } \\
\text { His.obj }\end{array}$ & $\begin{array}{l}616 \mathrm{~KB} \\
704 \mathrm{~KB} \\
525 \mathrm{~KB}\end{array}$ & $\begin{array}{l}\text { Lys.mtl } \\
\text { Arg.mtl } \\
\text { His.mtl }\end{array}$ & $\begin{array}{l}1 \mathrm{~KB} \\
1 \mathrm{~KB} \\
1 \mathrm{~KB}\end{array}$ & $\begin{array}{l}617 \mathrm{~KB} \\
705 \mathrm{~KB} \\
526 \mathrm{~KB}\end{array}$ & $1848 \mathrm{~KB}$ \\
\hline Aromatic & 3 & $\begin{array}{l}\text { Tyrosine } \\
\text { Tryptophan } \\
\text { Phenylalanine }\end{array}$ & $\begin{array}{l}\text { Tyr.obj } \\
\text { Trp.obj } \\
\text { Phe.obj }\end{array}$ & $\begin{array}{l}616 \mathrm{~KB} \\
704 \mathrm{~KB} \\
602 \mathrm{~KB}\end{array}$ & $\begin{array}{l}\text { Tyr.mtl } \\
\text { Trp.mtl } \\
\text { Phe.mtl }\end{array}$ & $\begin{array}{l}1 \mathrm{~KB} \\
1 \mathrm{~KB} \\
1 \mathrm{~KB} \\
\end{array}$ & $\begin{array}{l}617 \mathrm{~KB} \\
704 \mathrm{~KB} \\
603 \mathrm{~KB}\end{array}$ & $1924 \mathrm{~KB}$ \\
\hline $\begin{array}{l}\text { Polar } \\
\text { Unchar } \\
\text { ged }\end{array}$ & 6 & $\begin{array}{l}\text { Serine } \\
\text { Threonine } \\
\text { Asparagines } \\
\text { Glutamine } \\
\text { Cysteine } \\
\text { Proline }\end{array}$ & $\begin{array}{l}\text { Ser.obj } \\
\text { Thr.obj } \\
\text { Asn.obj } \\
\text { Gln.obj } \\
\text { Cys.obj } \\
\text { Pro.obj }\end{array}$ & $\begin{array}{l}362 \mathrm{~KB} \\
436 \mathrm{~KB} \\
471 \mathrm{~KB} \\
518 \mathrm{~KB} \\
369 \mathrm{~KB} \\
442 \mathrm{~KB}\end{array}$ & $\begin{array}{l}\text { Ser.mtl } \\
\text { Thr.mtl } \\
\text { Asn.mtl } \\
\text { Gln.mtl } \\
\text { Cys.mtl } \\
\text { Pro.mtl }\end{array}$ & $\begin{array}{l}1 \mathrm{~KB} \\
1 \mathrm{~KB} \\
1 \mathrm{~KB} \\
1 \mathrm{~KB} \\
1 \mathrm{~KB} \\
1 \mathrm{~KB}\end{array}$ & $\begin{array}{l}363 \mathrm{~KB} \\
437 \mathrm{~KB} \\
472 \mathrm{~KB} \\
519 \mathrm{~KB} \\
370 \mathrm{~KB} \\
443 \mathrm{~KB}\end{array}$ & $2604 \mathrm{~KB}$ \\
\hline $\begin{array}{l}\text { Non- } \\
\text { Polar }\end{array}$ & 6 & $\begin{array}{l}\text { Glycine } \\
\text { Alanine } \\
\text { Valine } \\
\text { Leucine } \\
\text { Isoleucine } \\
\text { Methionine }\end{array}$ & $\begin{array}{l}\text { Gly.obj } \\
\text { Ala.obj } \\
\text { Val.obj } \\
\text { Leu.obj } \\
\text { Ile.obj } \\
\text { Met.obj }\end{array}$ & $\begin{array}{l}263 \mathrm{~KB} \\
393 \mathrm{~KB} \\
482 \mathrm{~KB} \\
561 \mathrm{~KB} \\
562 \mathrm{~KB} \\
518 \mathrm{~KB}\end{array}$ & $\begin{array}{l}\text { Gly.mtl } \\
\text { Ala.mtl } \\
\text { Val.mtl } \\
\text { Leu.mtl } \\
\text { Ile.mtl } \\
\text { Met.mtl }\end{array}$ & $\begin{array}{l}1 \mathrm{~KB} \\
1 \mathrm{~KB} \\
1 \mathrm{~KB} \\
1 \mathrm{~KB} \\
1 \mathrm{~KB} \\
1 \mathrm{~KB}\end{array}$ & $\begin{array}{l}264 \mathrm{~KB} \\
394 \mathrm{~KB} \\
483 \mathrm{~KB} \\
562 \mathrm{~KB} \\
563 \mathrm{~KB} \\
519 \mathrm{~KB}\end{array}$ & $2785 \mathrm{~KB}$ \\
\hline
\end{tabular}

* VO is generated by the tool in the VR system.

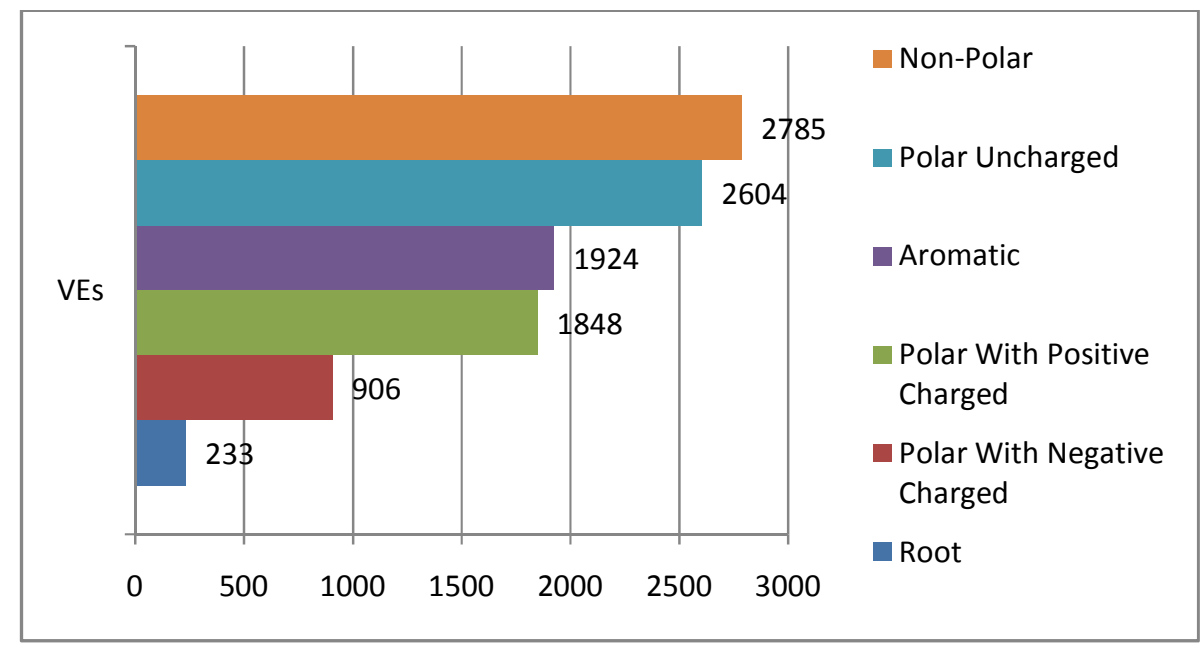

Figure 15. The file sizes of the projected VEs 
Based on Figure 15, the bar chart shows that the many uses of VOs in certain levels or VEs, the higher storages will be generated. The root VE produces $233 \mathrm{~Kb}$ for containing $1 \mathrm{OBJ}$ file format VO and 5 others primitive VOs created using the tool provided in the VR system. Polar With Negative Charged VE generates capacity of $906 \mathrm{~Kb}$ since it has 2 OBJ file format VOs. Meanwhile VE of Polar With Positive Charged produces higher capacity which is $1848 \mathrm{~Kb}$ for 3 OBJ file format VOs. A capacity of $1924 \mathrm{~Kb}$ is generated by Aromatic VE for 3 OBJ file format VOs. Polar Uncharged and Non-Polar VEs respectively produce $2604 \mathrm{~Kb}$ and $2785 \mathrm{~Kb}$ for containing 6 VOs. Even the number of VOs is equal but the more complex VOs will generate higher capacity.

\subsection{Usability Performance}

A usability study on the VR system in education has been conducted to evaluate in terms of the effectiveness, efficiency and usability existed and performed in the system as desired. A number of forty two undergraduate students with specification in Biology field had been selected for the study. The experiment had two sample quizzes for the students to familiarize with. They then tested the system and took a real quiz. After the completion of the quiz, they filled up a questionnaire to express their experiences. Inconvenience and difficulties encountered by the students during the interactions had been recorded. Identified factors for such problems could be used to improve the system or can serve as references to design and develop the future systems. The questionnaire had three sections; Demographic, Experience and System Usability Scale. The questionnaire utilized Likert scale style.

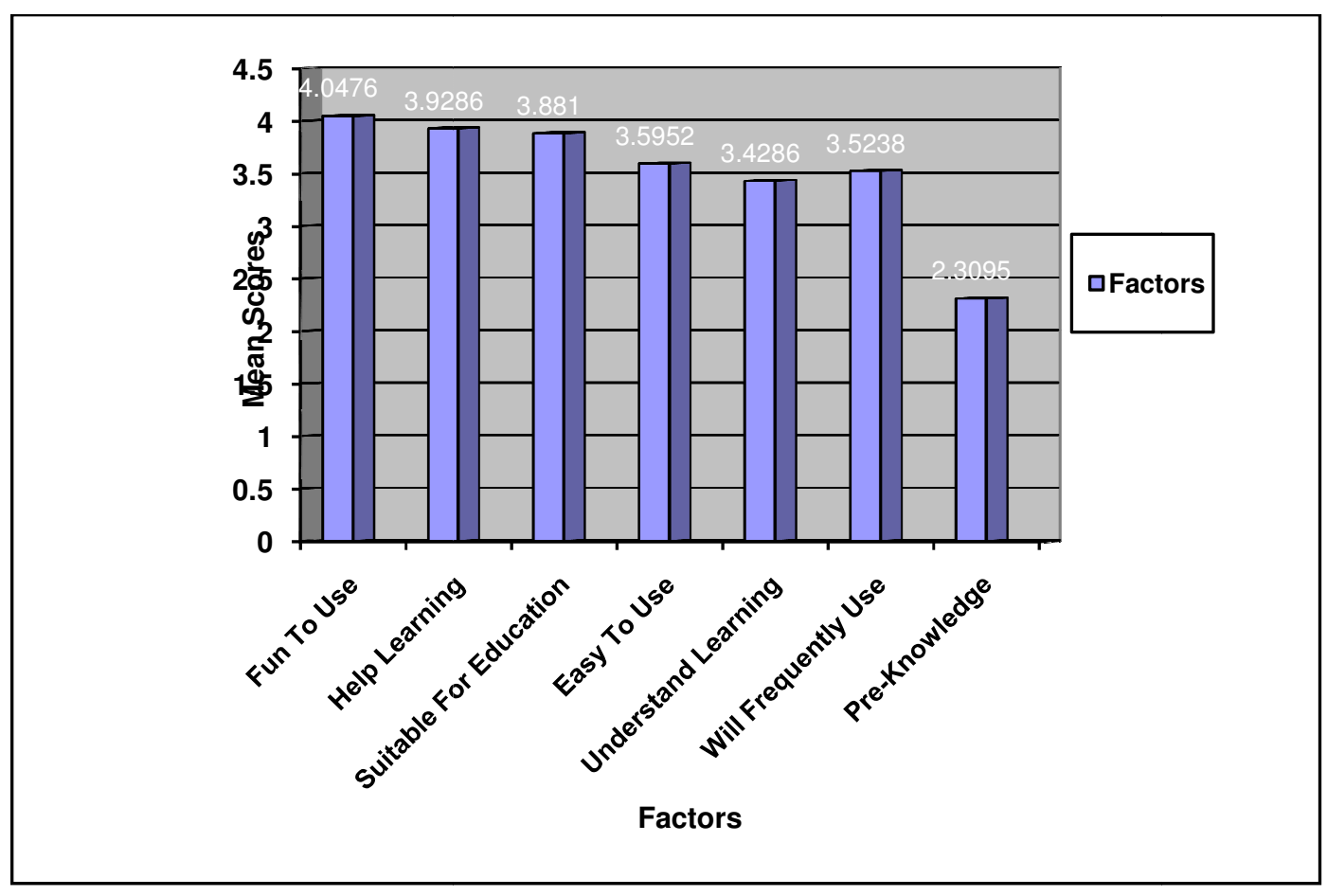

Figure 16 . The results of usability study

Figure 16 shows the mean scores of the responses in the usability study of the system. In general, the mean scores of the studied factors are above the level of point 3.000 except in the factor "PreKnowledge". The score in the factor "Fun To Use" is 4.0476 which mean the respondents highly 
The International Journal of Multimedia \& Its Applications (IJMA) Vol.3, No.2, May 2011

have fun using the VR system. Almost respondents state their agreements that the system can help them in education with the mean scores 3.9286 in the factor "Help Learning". In the factor "Suitable For Education", the respondents agree that the VR system is suitable to be used in education with the mean scores 3.8810. At the level of point 3.5952 in the mean scores of the factor "Easy To Use", the respondents respond that the system is easy to use. Meanwhile, the mean scores for the factor "Will Frequently Use" is at the level of point 3.5238 which mean the respondents are agree to use frequently the system in the future. They also can understand the subject due to the mean scores 3.4286 obtained for the factor "Understand Learning". However, with the mean scores at 2.3095 for the factor "Pre-Knowledge" show that the respondents need to learn the system firstly before they are able to master it.

\section{CONCLUSION}

This paper has presented a systematic technique called hierarchical, tree-structured approach for creating dynamic VEs and managing VOs in VE. Through this approach, several crucial VEs for the amino acids group have been created. Users are able to visualize, interact with VOs and walkthrough in the VE. To develop dynamic VEs in the VR system, four modules have been explained in detailed. Quantitative and qualitative data have been collected respectively to examine the use of capacity for each projected VE and to evaluate the usability of VR system using the proposed approach. The findings have shown that the VR system utilizing the Hierarchical, Tree-Structured approach is useful for teaching, easy and fun to use. The respondents have also indicated that they could understand the subject better using the system. Therefore, this approach may breed better understanding among students in their learning. We believe that many applications from various fields can be produced using this study including gaming, manufacture, architecture, medicine, entertainment etc.

\section{REFERENCES}

[1] Graces A., Quiros R., Chover M., \& Camahort C. (2010) "Implementing Virtual Agents: A HABA-Based Approach”, The International Journal of Multimedia \& Its Applications (IJMA). Vol.2, No. 4.

[2] Bell M.W., (2008) "Towards A Definition of Virtual World”, Journal of Virtual World Research. ISSN: 1941-8477. Vol. 1, No. 1.

[3] Nalbant G., \& Bostan B. (2006) "Interaction In Virtual Reality", 4th International Symposium of Interactive Medial Design (ISIMD).

[4] Sherman W. R., \& Craig A.B. (2003) Understanding Virtual Reality, Morgan Kaufmann Publishers. P-17.

[5] Burdea G., \& Coiffet P. (2003) Virtual Reality Technology. John Wiley \& Sons. P-2.

[6] Troyer O.D., Kleinermann F.,\& Ewais A. (2010) "Enhancing Virtual Reality Learning Environments with Adaptivity: Lessons Learned", USAB'10 Proceedings of the 6th International Conference on HCI in Work \& Learning, Life \& Leisure: Workshop HCI \& Usability Engineering Springer-Verlag Berlin, Heidelberg.

[7] http://www.ftsm.ukm.my/samn/PDFs/TH3813\%20 01\%20Pengenalan.pdf, Accessed on November 3, 2009.

[8] Leng J., (2001) “Scientific Examples of Virtual Reality and Visualization Applications”, UK High Performance Computing, Pages 1-13.

[9] Benjamin P. C. Yen., \& Kenny Y. M. Ng., (2003) Development and Evaluation of Dynamic Virtual Object Catalogs, Information And Management, No 40, Pages 337-349. 
The International Journal of Multimedia \& Its Applications (IJMA) Vol.3, No.2, May 2011

[10] Qiang L., Huanzhi L., Fei W., \& Boyan C., (2004) "Virtual Community Trials Platform”, Journal Of International Archives Of Photogrammetry Remote Sensing And Spatial Information Sciences, Vol 35, (4), Pages 1144-1147.

[11] Li J. R., Khoo L. P., \& Tor S. B., (2003) "Desktop Virtual Reality For Maintenance Training: An Object-Oriented Prototype System (V-REALISM)”, Elsevier-Computer In Industry, 52, Pages 109-125.

[12] Yuan M.L., Ong S.K., \& Nee A.Y.C. 2006. Assembly Guidance in Augmented Reality (AR) Environments Using a Virtual Interactive Tool. International Journal of Production Research. Vol. 46, No. 7, 1745-1767.

[13] Klein J., Krokowski J., Fischer M., Wand M., Wanka R., \& Heidi F. M. A. D., (2004) "The Randomized Sample Tree: A Data Structure for Interactive Walkthroughs in Externally Stored Virtual Environments", MIT Press Journal, Vol. 13, No. 6, Pages 617-637.

[14] Huang S., Baimouratov R., \& Nowinski W. L., (2004) "Building Virtual Anatomic Models Using Java3D”, Proceedings of the 2004 ACM SIGGRAPH international conference on Virtual Reality continuum and its applications in industry, Session: 7-3 Modeling, Pages $402-405$.

[15] http://en.wikipedia. org/wiki/Tree_data_structure. Accessed on April 10, 2008

[16] Goodrich M. T., \& Tamassia R., (2010) Data Structure And Algorithms In Java, John Wiley \& Sons Inc, USA.

[17] Preiss B. R., (2000) Data Structure And Algorithms With Object-Oriented Design Patterns In Java, John Wiley \& Sons, Inc, USA.

[18] Millar T., (2002) Biochemistry Explained: A Practical Guide To Learning Biochemistry, Gutenberg Press Ltd, Malta.

[19] Polanski A., \& Kimmel M., (2007) Bioinformatics, Springer-Verlag Berlin Heidelberg, New York.

[20] Bhagavan N. V., (2002) Medical Biochemistry-Fourth Edition, Harcourt/Academic Press, Canada.

[21] Pamela C. C., Richard A. H., \& Denise R. F., (2005) Biochemsitry, Lippincott Williams \& Wilkins, USA.

[22] http://en.wikipedia.org/wiki/Obj, Accessed on August 6, 2008.

[23] http://www.fileformat.info/format/wavefrontobj/, Accessed on August 6, 2008.

\section{Author}

Wan Mohd Rizhan Wan Idris is a Multimedia lecturer in Faculty of Informatics under the department of Multimedia in Universiti Sultan Zainal Abidin, Terengganu, Malaysia. He obtained Master of Science in Computer Science from Universiti Malaysia Terengganu since 2010. His focused areas are on virtual reality, 2D and 3D animations.

Elissa Nadia Madi obtained her Master of Mathematics (Fuzzy Set) from Faculty of Science and Technology, Universiti Malaysia Terengganu in 2009. Currently, she is a Lecturer at Department of Information Technology, Faculty of Infomatics, Universiti Sultan Zainal Abidin, Terengganu, Malaysia. 